\title{
Effect of Socioeconomic Status on Emersion Adolescent Creativity
}

\author{
Zahra Parsasirat ${ }^{1}$, Amir Foroughi ${ }^{2}$, Fatimah Yusooff ${ }^{1}$, Nasrudin Subhi ${ }^{1}$, Salina Nen ${ }^{1} \&$ Hadi Farhadi $^{1}$ \\ ${ }^{1}$ School of Psychology and Human Development, Faculty of Social Sciences and Humanities, National \\ University of Malaysia, Bangi, Malaysia \\ ${ }^{2}$ Faculty of Education, National University of Malaysia, Bangi, Malaysia \\ Correspondence: Zahra Parsasirat., School of Psychology and Human Development, Faculty of Social Sciences \\ and Humanities, Universiti Kebangsaan Malaysia, 43600 UKM Bangi, Selangor, Malaysia. Tel: \\ 98-912-830-3594. E-mail: z_parsasirat@yahoo.com
}

\author{
Received: January 20, 2013 Accepted: February 7, 2013 Online Published: March 28, 2013
}

doi:10.5539/ass.v9n4p105

URL: http://dx.doi.org/10.5539/ass.v9n4p105

\begin{abstract}
Prior research has attempted to investigate creativity as a behavior resulting from the interaction between the cognitive abilities, social environment and personal characteristics, but very little research has look at the role of environment characteristics on Emersion Adolescent Creativity. Hence, this article focuses on the effect of socioeconomic status on emerging adolescent creativity. In other words, family economic status, father's education and mother's education are the three dimensions of socioeconomic status. This exploratory correlational research study examines the relationship between family economic status, father's education and mother's education with adolescent creativity. The sampling method was employed to select the proportion of participants using stratified and multi-stage cluster random sampling. The population of the sample was 546 high school students in Education Region 4, Tehran. The participants, 249 males and 297 females, completed two questionnaires. The adolescents completed a Demographic Characteristics Questionnaire and Abedi Creativity Questionnaire, which were used as the measuring tools in this study. The results show a significant positive correlation between family economic status and creativity $(\mathrm{p}<.01)$, and between parent education and creativity $(\mathrm{p}<.01)$. Interestingly, the analyses revealed a strongly significant positive correlation between parent education and creativity $(\mathrm{p}<.01)$, although none was found between males and females on creativity. Conclusions were tempered by the limitations of small to moderate correlations and small effect sizes.
\end{abstract}

Keywords: socioeconomic status, family economic status, father education, mother education, creativity, adolescent

\section{Introduction}

Without doubt every child is born with certain traits; however, it is up to the environment to nurture and develop these traits. Creativity is one of these traits, although, some researchers believe that creativity is dependent upon both inherent and biological factors (for example, Karlsson 1978).However, others think that the environmental factors are important (Shariatmadari, 1983; Ghaemi, 1985; Guilford, 1962; Dawson, 2009). Although there is controversy concerning the definition of creativeness, according to Torrance (1970) most scholars agree that creativity is one of the highest forms of cognitive functioning, and, also, that there is a positive correlation between creativity and high achievement. According to Shimm \& Ballen (1996), every child is born with the potential to be creative. Hence, it is important how that child is nurtured, as it will increase or decrease the potential nature. Parents, teachers or other people need a good environment for nurturing and teaching everything, or, at least a good environment is a facilitator.

Godel (2006) claimed that socioeconomic status could have a strongly important impact on a family home and how parents behave with their children. In other words, usually, families with lower socioeconomic status have many economic hardships that cause stress and can interfere with their parenting abilities. In contrast, families in a high socioeconomic group demonstrate that parents have more time to spend with their children. Also, lower socioeconomic status households experience extra stress, which can cause parents to use more punitive parenting practices. Moreover, Bradly and Corwyn (2002) reported that the families with a high socioeconomic status have more conversations than those from the low socioeconomic status, as well as read more, and provide more teaching experiences for their children (cited by Godel, 2006). 
Moreover, Mouchiroud and Lubart (2001) reported that lower socioeconomic situations may need longer instruction in creativity, and, also, Salemi (2010) suggested important recommendations for future research including comparing levels of creative students among different socioeconomic groups. The main questions addressed in this paper are: a) Is there a relationship between family economic status and creativity among high school students? b) Is there a relationship between parents' education (father/mother) and creativity among high school students, and which parents have more influence on creativity? C) Is there a significant difference in the mean creativity scores for males and females?

\subsection{Literature Review}

A considerable amount of literature has been published on creativity. Although there is not much research about the impact of socioeconomic status on emersion creativity, Dudek and Runco (1993) conducted a research on the above subject. They explored the differences in creative thinking skills among children representing different socioeconomic levels. In their research, 1,500 students' from11 schools were chosen as participants. Ultimately, they found a statistically positive significance between the potential creativity in children and socioeconomic status. In other words, they demonstrated that high quality material environments increase the potential creativity. Furthermore, in 1991 a relationship between children's creativity and the occupational level of mothers was reported by Michel and Dudek, in fact, mothers of less creative children had a significantly lower job level than mothers of more creative children, however, in this study were not explore directly different levels of socioeconomic.

Kfayt (1995) demonstrated the impact of different socioeconomic levels (welfare, average and low social status) on creativity. He selected 225 male students who enrolled in the first year of secondary school. They used ANOVA, multivariate regression, and Tukey multiple comparisons to analyses the data collected. The results show that there was a statistical difference between three socioeconomic levels (welfare, average and low social status) and creativity. Also, there was a statistically different mean of creativity between welfare socioeconomic level and average and low socioeconomic level; however, there was no statistically different mean of creativity between average socioeconomic level and low socioeconomic level. The subject was previously explored in 1999 by Hellen, who selected 52 preschool students ( 29 males and 23 females) to explain influence of maternal attitudes on the creativity level of children who were three to six years old. Hellen reported differences between socioeconomic levels and creativity. The Pearson's product moment correlations revealed that significant creativity and control subscales were positively correlated with socioeconomic status.

Sidhu (1993) investigated the differential impact of the culture of poverty on the development of children's intellectual and non-intellectual characteristics of personality. For this study, 540 boys aged between eight and ten studying in the fourth and fifth grades in the public, government and slum schools of Ludhiana district were selected. Raven's coloured progressive matrices, and examination marks awarded by the class teachers were used as measures of academic achievement. In addition, Udai Parek's picture frustration test and level of aspiration coding test by Ansari and Ansari were used as measuring tools. Furthermore, statistical analyses were accomplished using the chi-square test. The results showed that in the government and slum schools, boys' creativity scores were statistically positively significant with the fathers' education whereas the total creativity scores of public school boys were not statistically significant with the fathers' education.

The findings of KeyneHor Yee Iu (2003) were similar to Sidhu's results (1993). In this study, to determine the impact of parental guidance of children's behavior about TV viewing and non-TV viewing activities 98 primary school Grade 2 children were selected as participants. Researcher to measure the samples' creativity level was used a revised version of the Wallach-Kogan creativity tests. Moreover, parents determined behavior of their children about TV viewing habits. Finally, the results of hierarchical regression analyses illustrated positive significant predictors of children's creativity by parental monitoring and fathers' education level while it was illustrated negative significant predictor of children's creativity by parental moderation.

Other researchers that studied the effect of fathers' education on creativity were Ozgun et al. (2011). They chose 24 fathers who had children of6-years-old and enrolled in a kindergarten in a public school setting in Turkey as participants. This study was a quasi-experimental multi-group in which12 fathers were assigned to an experimental group while 12 fathers were assigned to the control group, before the fathers in the experimental group enrolled in the fathers' education programs. In addition, both groups (experimental and control groups) completed a pre-test and post-test. After comparing the pre-test and post-test, the results showed a significant difference between the experimental and the control group concerning creativity.

In addition, in respect of the effect of mothers' education on creativity, Brophy (1970) reported that mothers' teaching strategies with their children have been connected to maternal educational background and 
socioeconomic status level. Also, Laosa (1978) found a positive relation between mothers' education and creativity. After analyses of the data by chi-square, Sidhu (1993) reported that in the public, government and slum schools the total creativity scores of boys was not associated significantly with the mothers' education. Heinla (2006) supported Sidhu's results (1993). Comparative results between 16-17 year-old and 9-12 year-old showed Estonian adolescents' social environment with their creative thinking were connection. Heinla reported in the 16-17 year-old adolescents creative thinking is higher when one or both parents have work as top executives or specialists or even have high level of university education. However, when the mothers have a higher education for the 9-12 year-old children, groups, the creative thinking is higher.

Dudek and Runco (1993) reported a difference in the mean score creativity between males and females. They chose 1,500 students in 11 schools and explored the differences in sex in the development of the creativity potential. They found that the mean score of creativity was different between boys and girls and also reported that the creative potential improved with age. In addition, Naderi et al., in 2009, found similar results in Malaysia. They explored the effect of a few predictors including gender, creativity, and age with academic achievement in 153 undergraduate students in Malaysian universities. The age of participants who completed the creativity test ranged from 18 to 27 years old. The results show that the females' mean score (33.21) was greater than the males' mean score (31.90) for creativity, however, no large differences in the standard deviations were found between females and males (females $=4.55 \&$ males $=4.36$ ). Trivedi and Bhargava (2010) found that in high achiever groups, when gender was differences, gender impact on creativity was observed. In other words, these groups of adolescents were more alike and shared similar traits that override the impact of gender. In contrast, among the low achiever group on creativity there were differences according to gender. They selected 240 students, (120 male and 120 female) aged 15 to 17 years from Senior Secondary schools in Jodhpur city. Passi's Test of Creativity (PTC) and the percentage of aggregate marks were used for data collection.

However, in contrast to the above, over20 years, researchers have determined that there is no difference in creativity in males and females (Javid, 1994; Samiei, 2003 and Ahmadiian, 2006). In 1994, research concerning the family and the emotional and creativity of children was conducted by Javid. In this research, male and female students from several Education regions were selected including regions 3, 4, 5, 6 and 7, using random sampling. Data collection was used for the creativity test and the family emotional climate questionnaire, also statistically analysis - multiple regression methods and t-test - were conducted. According to the statistical analysis, the current study illustrated no significant different mean score of creativity between males and females. Samiei (2003) supported the results of Javid's study; however, she conducted her study on the psychological profile of creative and non-creative sciences and arts students in the public universities in Tehran. Participants were selected using the random sampling model;300 students (150 males and 150 females) who enrolled in the universities in Tehran and completed the questionnaires were chosen as participants. The independent sample t-test and Pearson product-moment correlation were conducted as the analysis data in this study. The results illustrated that although arts students had higher scores there was no statistically significant difference between the science students and the arts students concerning the creativity in the universities. The results also showed that there was no difference in creativity between males and females.

Another research that supported the prior results was conducted by Ahmadiian in 2006. This research concerned the relationship between self-efficacy, creativity and different courses in adolescents. Using random stratified sampling388 participants were selected from grades 2 and 3 high school and pre-university. Statistical analyses were used including Pearson's product-moment correlation, independent-sample t-test and two-way ANOVA. Finally, the results illustrate that there was no statistically significant difference in creativity between males and females.

\section{Method}

\subsection{Procedure and Sampling}

In order to do this study, after obtaining official permission from the Department of Education Region 4,the number of students (546 students were chosen from approximately 41,050 students, $1.33 \%$ ) and the number of schools were determined. In fact 546 students (249 males and 297 females) who enrolled in a second degree in high school in Education Region 4 in Tehran were selected. The participants were selected on the basis of stratified and multi-stage cluster random sampling. The researcher coordinated with high school administrators to visit the schools and explain the importance and objectives of the study to the students; questionnaires were given to the students and the desired information was collected. It was necessary to complete the entire questionnaire; even if one question was not answered, the whole questionnaire was excluded and only data from complete questionnaires were entered and collected by SPSS. The data collected were tabulated and statistically 
treated to arrive at a meaningful inference.

\subsection{Instrument}

In the present study two instruments were used: A self-constructed background information sheet was used to collect information about the details regarding family economic status, education of father and mother. Family economic status was determined using five alternatives (Wealthy - upper class, Comfortable - upper middle class, Comfortable - middle class, Getting by - lower middle class, Financially strained - poor); also fathers' education and mothers' education were determined based on the completed level of education in separate questions for father and mother (Some High School, High School Graduate, Some College/Vocational Training, College Graduate, Some Postgraduate Education).

Creativity was measured using the Abedi Creativity Questionnaire (1993). This questionnaire is based on the Torrance Creativity Questionnaire and has 60 questions; each question has three different alternatives. Validity has been tested several times by a number of researchers (Abedi 1993, Mhrafrvz 1999, Kfayt 1995, Samiei 2003, Mhrafza 2004 and Ahmadiian2007). In respect of prior research, 0.85reliability was reached by Abedi 1993, and 0.93 for this research.

\section{Data Analysis and Results}

Data were analyzed through the correlation between the subscales of socioeconomic status and creativity to identify the relation between non-parametric variables (family economic status, father education and mother education) and the parametric variable (creativity). To find whether the connection between the variables is the result of chance or not, analyzers used bivariate analysis with an explanation of significant tests. The bivariate correlation is a measurement of the strength of the relationship between two variables, whereas the non-parametric alternative for Pearson correlation coefficient is Spearman's rho correlation coefficient (Lay $\&$ Khoo, 2009). The Spearman's rank order correlation (rho) coefficient between the variables of family economic status and creativity were examined in terms of statistical significance at the 0.05 alpha level. As indicated in table (1) since the probability value (sig.000) is less than the predetermined alpha value (.05), the null hypothesis was rejected. There exists adequate evidence to show that $\mathrm{p}<.01$. There is a significant positive relationship between family economic status and students' creativity. This conclusion is made at the significance level of $\alpha=.05(5 \%)$ or confidence level (95\%). This means that the level of family economic status influences students' creativity.

Table 1. Correlation

\begin{tabular}{llll}
\hline Variables & & & Creativity \\
\hline Family Economic status & Spearman & 1.000 & $.285^{* *}$ \\
& Correlation & & .000 \\
& Sig.(2-tailed) &. & $.324^{* *}$ \\
Father Education & Spearman & 1.000 & .000 \\
& Correlation & & $.350^{* *}$ \\
Mother Education & Sig.(2-tailed) &. & .000 \\
& Spearman & 1.000 & 546 \\
& Correlation & & \\
& Sig.(2-tailed) &. & \\
& $\mathrm{N}$ & 546 & \\
\hline
\end{tabular}

** Correlation is significant at the 0.01 level (2-tailed)

The Spearman's rank order correlation (rho) coefficient between the variables of father education and creativity were examined in terms of statistical significance at the 0.05 alpha level. Since the probability value obtained from SPSS (sig.000) is less than the predetermined alpha value (.05), the null hypothesis was rejected. There exists adequate evidence to show that $\mathrm{p}<.01$.There is a significant positive relationship between fathers' education and students' creativity. This conclusion is made at the significance level of $\alpha=.05$ (5\%) or confidence level (95\%).This means that the level of father's education influences students' creativity. The Spearman's rank 
order Correlation (rho) coefficient between the variables of mothers' education and creativity were examined in terms of statistical significance at the 0.05 alpha level. As indicated in table (2), since the probability value (sig.000) is less than the predetermined alpha value (.05), the null hypothesis was rejected. Adequate evidence exists to show that $\mathrm{p}<.01$.There is a significant positive relationship between mothers' education and students' creativity. This conclusion is made at the significance level of $\alpha=.05(5 \%)$ or confidence level (95\%).This means that the level of mother's education influences students' creativity.

Table 2. Group statistics

\begin{tabular}{llllll}
\hline & Gender & $\mathrm{N}$ & Mean & Std. Deviation & Std. Error Mean \\
\hline Creativity & Males & 249 & 132.95 & 19.43 & 1.23 \\
& Females & 297 & 134.68 & 16.48 & .95 \\
\hline
\end{tabular}

Furthermore, for exploring the difference in creativity between male and female high school students the independent sample t-test was used. Statistical tests were used to determine whether there is a significant difference in the mean of two independent samples (Lay \&Khoo, 2009). Data were analyzed through the independent sample t-test in the mean creativity between male and female students. As indicated in table (2), since the probability value is (.26), which is higher than the predetermined alpha value (.05), the null hypothesis was accepted. Adequate evidence exists to show that there is no significant difference in the mean creativity between male and female students. This conclusion is made at the non significance level of $\alpha=.05(5 \%)$ or confidence level $(95 \%)$. There is not a significant difference in the mean creativity between male and female students (see Tables $2 \& 3$ ).

Table 3. Independent samples t-test

\begin{tabular}{|c|c|c|c|c|c|c|c|c|c|}
\hline & & \multicolumn{2}{|c|}{$\begin{array}{c}\text { Levene's Test for } \\
\text { Equality of } \\
\text { Variances }\end{array}$} & \multicolumn{6}{|c|}{ t-test for Equality of Means } \\
\hline & & \multirow{2}{*}{\multicolumn{2}{|c|}{ Sig. }} & \multirow[t]{2}{*}{$\mathrm{t} \quad \mathrm{df}$} & \multirow[t]{2}{*}{$\begin{array}{c}\text { Sig. } \\
\text { (2-tailed) }\end{array}$} & \multirow[t]{2}{*}{$\begin{array}{c}\text { Mean } \\
\text { Difference }\end{array}$} & \multirow[t]{2}{*}{$\begin{array}{l}\text { Std. Error } \\
\text { Difference }\end{array}$} & \multicolumn{2}{|c|}{$\begin{array}{l}95 \% \text { Confidence } \\
\text { Interval of the } \\
\text { Difference }\end{array}$} \\
\hline & & & & & & & & Lower & Upper \\
\hline \multirow{2}{*}{ Creativity } & $\begin{array}{c}\text { Equal } \\
\text { variances } \\
\text { assumed }\end{array}$ & 12.274 & .000 & -1.127544 & .260 & -1.73 & 1.53 & -4.75 & 1.28 \\
\hline & $\begin{array}{c}\text { Equal } \\
\text { variances not } \\
\text { assumed }\end{array}$ & & & -1.110488 & .267 & -1.73 & 1.55 & -4.79 & 1.33 \\
\hline
\end{tabular}

\section{Discussion}

As mentioned previously, the aim of the follow-up study was to determine whether family economic status, fathers' education and mothers' education impact on creativity, and, if so, which one has more effect on creativity in adolescents. Also it was found that there was a difference in creativity between male and female high school students. The results of this study supported the major hypothesis of this study, the statistical analysis of the follow-up study showed a statistically positive significant difference between variables, namely, family economic status, father's education and mothers' education impact on creativity. In addition, the independent sample t-test showed a statistically non-significant difference in creativity between male and female students. The correlation table (1) reports the Spearman's rho correlation coefficient for the relationship between family economic status and creativity. There is a positive relationship between family economic status and adolescents' creativity. The value of 'Sig. (2-tailed)' (.000) is less than the predetermined alpha value 
$(.05 / 2=.025)$, thus, the stated null hypothesis was rejected. Adequate evidence exists to show that there is a significant positive relationship between family economic status and creativity. This conclusion is made at the significance level of $\alpha=.05$ (5\%) or confidence level (95\%). This result is similar to the aforementioned findings (Michel \& Dudek, 1991; Dudek \& Runco, 1993; Kfayt, 1995). According to the report by Michel and Dudek (1991) there is a relationship between children's creativity and mothers' occupational level, in that the mothers of highly creative children had a significantly lofty job level compared to the mothers of less creative children. These results support Dudek and Runco (1993), who found that there was a positive relationship between the potential creativity in children and socioeconomic status. Furthermore, the quality of the material environment (high socioeconomic status) increases the potential creativity. Although the results of the research of Kfayt (1995) did not show a clear relationship between the difference in three levels of socioeconomic status, he claimed the variance in the difference between the three levels of socioeconomic status (welfare, average and low social status) and creativity demonstrated that there are differences between these levels. Hellen (1999) supported the previous results, and said that there were significant differences between socioeconomic levels with creativity in children.

Moreover, a survey of the relation between fathers' education and creativity showed a positive relationship. The correlation reports the Spearman's rho correlation coefficient for the relationship between fathers' education and creativity. The null hypothesis was rejected as the value of 'Sig. (2-tailed)' (.000) is less than the predetermined alpha value $(.05 / 2=.025)$. Adequate evidence exists to show that there is a significant positive relationship between fathers' education and creativity. This conclusion is made at the significance level of $\alpha=.05(5 \%)$ or confidence level (95\%) (see Table1). The present findings seem to be consistent with other research that found that there was a positive relationship between fathers' education and creativity in families with low income (Ozgunet al., 2011). Also Keyne Hor Yee Iu (2003) reported that fathers' education level was a positive predictor of children's creativity. Furthermore, in 1993, Sidhu illustrated that in the government and slum schools, boys creativity scores were significantly associated with the fathers' education, while, in contrast, in the public schools, boys total creativity scores were not significantly associated with the fathers' education.

The Spearman's rho correlation coefficient was used for the relationship between mothers' education and creativity among high school students. There is a positive relationship between mother education and adolescents' creativity. The value of 'Sig. (2-tailed)' (.000) is less than the predetermined alpha value $(.05 / 2=.025)$; thus, the stated null hypothesis was rejected. Adequate evidence exists to show that there is a significant positive relationship between mother's education and creativity. This conclusion is made at the significance level of $\alpha=.05(5 \%)$ or confidence level (95\%). As to the aforementioned findings in this research, in 1970, it was reported by Brophy that mothers' teaching strategies with their children was connected to maternal educational background and socioeconomic status level. There are similarities between mothers' education and creativity by Laosa (1978). Hellen (1999) claimed that maternal attitudes could eventually affect the learning process of children. Contrary to the aforementioned findings, Sidhu (1993) reported that the total creativity scores of public, government and slum schoolboys were not significantly associated with the mothers' education. In contrast, prior research by Heinla (2006) claimedthat in the 16-17 year-old adolescents creative thinking is higher when one or both parents have work as top executives or specialists or even have high level of university education, where their families live in the capital and they cope well economically.

As noted above, after exploring about fathers' and mothers' education, parent's education was compared. The results showed that, in this study, mothers' education had a stronger effect than fathers' education, in spite of the fact that these had low differences. These results are contrary to Sidhu's results in 1993 that heighted father education, the researcher reported there was a statistically significant relationship between total creativity scores in the government and slum school boys with fathers' education; however, the researcher did not find a statistically significant relationship between total creativity scores in the government and slum school boys with mothers' education. Sidhu chose poor Ludhiana students as participants, and found that culture and the same economic position could produce different results.

Finally, the current study compared the difference in creativity in males and females, which showed that the mean degree of creativity between males and females is similar. According to Tables 3 and 4 , there is no significant difference in the mean score of creativity between male and female high school students. In addition, male and female students are equal in creativity. The present findings seem to be consistent with other research, which found that there was no significant difference in the creativity scores between male and female students (Javid, 1994; Samiei, 2003; Ahmadiian, 2006). In contrast with these results, in 2009, Naderi et al found a feeble difference in creativity between males and females. He claimed that the females' mean score was greater than the males' mean $($ males $=31.90 \&$ females $=33.21)$ for creativity, however, there were no large differences in the 
standard deviations between females (4.55) and males (4.36). Likewise, Dudek and Runco (1993) illustrated that there is a significant difference between boys and girls in respect of creativity.

\section{Conclusion}

The follow-up study, after measurements for family economic status, fathers' education, mothers' education and creativity results, showed that although all the variables impact on creativity, parent's education, especially mothers' education is more important to increase creativity in adolescents. Future research will provide more precise answers concerning how to increase the potential skills in children, especially creativity, and how it can provide equal education for all students, as well as the long-term effects on those adolescents who have low family economic status or have low literacy during their school years.

\section{Acknowledgements}

Authors would like to thank all of their lectures who guide them during this study and also all their friends who helped them. Their Kindness and guidelines cannot be forgotten in authors' life.

\section{References}

Brophy, J. E. (1970). Mothers and teachers of their own preschool children: The influence of socioeconomic status and task stretchers on teaching specificity. Child Development, 41, 79-94. http://dx.doi.org/10.2307/1127390

Chien, C. Y., \& Hui Anna, N. N. (2010). Creativity in early childhood education: Teachers' perceptions in three Chinese societies. Journal of Thinking Skills and Creativity, 5(2), 49-60. http://dx.doi.org/10.1016/j.tsc.2010.02.002

Dudek, S. Z., \& Runco, M. A. (1993). Cumulative and proximal influences on the social environment and children's creative potential. The Journal of Genetic Psychology, 154(4), 487-499. http://dx.doi.org/10.1080/00221325.1993.9914747

Fah, L. Y., \& Hoon, K. C. (2009). Introduction to statistical analysis in social sciences research (Series 2). Malaysia, Venton Publishing (M) Sdn. Bhd.

Godel, E. (2006). Relationship between parenting and discipline styles and socioeconomic status. M.Sc. thesis, California State University, Long Beach.

Guilford, J. P. (1962). Creativity: Its measurement and development. In J. J. Parnes, \& H. F. Harding (Eds.), $A$ source book for creative thinking. New York: Scribners.

Heinla, E. (2006). Creative thinking of adolescents in Estonian society. Nordic Journal of Youth Research, 14(3), 235-255. Retrieved from http://you.sagepub.com/content/14/3/235.abstract

Hellen, K. A. (1999). Maternal attitudes and their influence on the creativity level of preschool children. M.Sc. thesis, West Virginia University.

Hojjatollah, M. (1999). Relationship between attitudes maternal child rearing (authoritative, authoritarian, permissive) with the local control and academic achievement in fourth grade primary school students. MA thesis, Tarbiat Moallem of Tehran University.

Iu, K. H. Y. (2003). Relationship between Hong Kong children's creativity and their television viewing habits. Department of Applied Social Studies. Retrieved from http://dspace.cityu.edu.hk/handle/2031/3567

Javid, K. J. T. (1994). The relationship between emotional family atmospheres with children's creativity. MA thesis, Modares University.

Karlsson, J. L. (1978). Inheritance of Creative Intelligence. Chicago: Nelson-Hall, Inc.

Laosa, I. M. (1978). Maternal teaching strategies in Chicano families of varied educational and socioeconomic levels. Child Development, 49, 1129-1135. http://dx.doi.org/10.2307/1128752

Mehrnaz, M. (2004). The relationship between child rearing methods with creativity and academic achievement on high school students through 2003-2004. MA thesis, University of Tabriz.

Mohammad, K. (1995). The relationship between parenting attitudes with creativity and also the relationship between parenting attitudes with intelligence and academic achievement. MA thesis, Shahid Chamran University

Naderi, H., Abdullah, R., Tengku, A. H., Sharir, J., \& Kumar, V. (2009). Creativity, age and gender as predictors of academic achievement among undergraduate students. Journal of American Science, 5(5), 101-112. 
Ozgun, O., Bolat, E. Y., Ciftci, M. A., \& Erden, S. (2011). Impacts of Father Education on Low-income Turkish Fathers' Parenting Attitudes and Behaviors. Conference: ECER 2011, Urban Education. Retrieved from http://www.eera.de/index.php?id=421\&no_cache=1\&Action=showContributionDetail\&conferenceUid=5\& contributionUid $=7233 \& \mathrm{cHash}=84787641 \overline{\mathrm{db}}$

Salemi, M. L. (2010). Utilizing fluency, flexibility, originality, and elaboration to enhance creativity and vocabulary use for improving reading comprehension in third through sixth grade students. $\mathrm{PhD}$. Thesis, Union University.

Samira, S. (2003). Compare mental profiles of creative and non-creative in sciences and arts students in the public universities in Tehran. MA thesis, Alzahra University.

Sidhu, K. (1993). Investigation into the effects of the culture of Poverty on development of Children's Intellectual and Non-intellectual Characteristics of Personality. Ph.D thesis, Guru Nanak Dev University.

Taha, A. (2007). The relationships between self efficacy, creativity and academic achievement in high school students. MA thesis, Shahid Behashti University.

Trivedi, K., \& Bhargava, R. (2010). Relation of creativity and educational achievement in adolescence. Journal of Psychology, 1(2), 85-89. 